\title{
Work in Progress - A Design Guide to Retain Female (and Male) Students In Engineering
}

\author{
Linda Vanasupa, Katherine C. Chen, Stacey Breitenbach, Karen R. Bangs \\ California Polytechnic State University, lvanasup@calpoly.edu, kcchen@calpoly.edu, sbreiten@calpoly.edu, \\ krbangs@calpoly.edu
}

\begin{abstract}
Despite a rich body of research on factors contributing to attrition of women during the college, women continue to be underrepresented in the graduating classes of most traditional engineering disciplines. We present our Four-Domain Development Diagram (4DDD) in an attempt to enable a systems approach to managing all the factors that contribute to retention. This diagram makes explicit the connections between the learners' response factors in the learning environment, including motivation, interest, and ultimately retention. Although we are only three years into our use of the diagrams' relationships, we have seen a lower overall net attrition rate (male and female) from freshman year from $\sim 50 \%$ to $\sim 20 \%$, seeing a net influx of female students, from numbers as low as 2 of 44 in the entering freshmen cohort to 6 out of 40 (now sophomores) in that same cohort. In this paper, we present the diagram, briefly introduce the theoretical underpinnings with preliminary quantitative and qualitative data.
\end{abstract}

Index Terms - curricular design, educational psychology, learning, retention.

\section{INTRODUCTION}

Since 1985, the overall percentage of bachelor degrees awarded in the United States to females in engineering has not significantly increased beyond roughly 20\% [1]. Programs that have broken this percentage barrier, such as biomedical engineering and environmental engineering [1], have an obvious direct connection to helping society, a value that women across the world consistently rank higher than their male counterparts [2]. Recent studies also provide evidence that the perceived misalignment of engineering content and personal values is just one of many factors that contribute to the disproportionately large loss [3] of females in the science and engineering career pipeline. Aside from the myriad of social issues, such as students' beliefs around learning $[4,5]$, that influence all students' ability to learn prior to college, cultural issues within the engineering learning experience are emerging as strong contributors to the loss of individuals who diversify the engineering profession [6,7]. While faculty cannot control some of the historical social influences on students, we are able to alter curricular content and the learning process to appeal to underrepresented populations of students in a way that enhances the educational experience (and retention) of all students.

We sought to create a design tool for effective engineering learning experiences. Our model of learning, the Four-Domain Development Diagram (4DDD) makes use of the vast body of literature on educational psychology. This diagram brings together the multiple, interacting causal relationships that have been shown to influence students' whole development: cognitive, psychomotor, social and affective. The underlying premise of the 4DDD is that by designing experiences with principles of good learning, faculty can leverage their combined effects.

\section{The Four-DomaIn DeVelopMent Diagram}

The 4DDD is depicted in Figure 1. (The empirical and theoretical underpinnings of the model have been presented in detail elsewhere [8].) It is a causal loop diagram, a graphic tool derived from the systems thinking literature. The backdrop of the causal loop diagram is a schematic of the learner's development within left-brain dominant domains (cognitive and psychomotor) and right-brain dominant domains (social and affective). At the center is a circle that represents intrinsic motivation for learning, symbolically placed at the center of the students' whole development. The strength of the learner's movtivation is dictated by the reinforcing interaction (indicated by the " $R$ " in the center) of the students' interest in what is being learned, their value of it and autonomy that they experience in the learning environment. The "s" at the head of the arrow indicates that changes in one construct cause changes in the other in the same direction. These individual causal relationships have been established by other researchers (see [8]); Vanasupa et al. have mapped them together in the 4DDD [8] as a way to holistically view the learner's development. Each term (e.g., interest) can be thought of as a gauge for that construct, with the arrows indicating how changes in that construct affect changes in the others.

The constructs outside of motivation circle represent several pathways to what we would identify as the two critical areas of development for the $21^{\text {st }}$ century engineer: mastery in their discipline, and moral and ethical development to guide the application of their disciplinary expertise. The pathway to both of these is engagement or active learning, a mechanism that is supported by learning research and theory (for a review, see [9]). 


\section{Session T4D}

Other factors which influence the strength of students' motivation, and ultimately learning and retention are students' sense of belonging and safety in the learning environment (relatedness) [12] and being able to see the connection between what they are learning and the world around them (understanding the broader context) [11]. We are proposing the connection of systems thinking shown on the diagram.

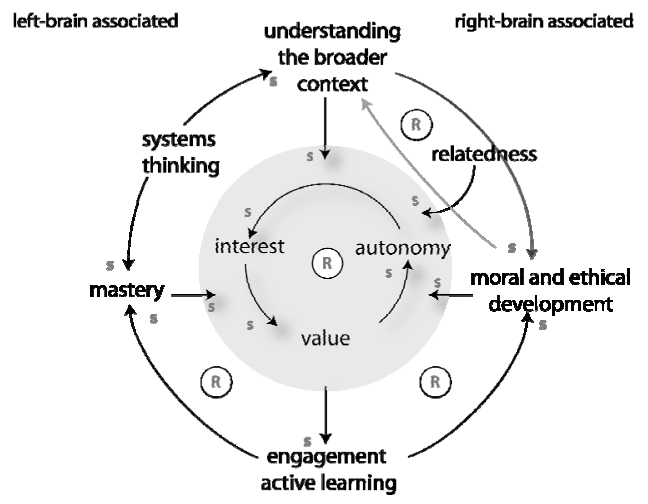

FIGURE 1

THE FouR-DOMAIN DEVELOPMENT DiAGRAM.

\section{Preliminary Results}

The relationships within this diagram were used to holistically redesign multiple learning experiences (e.g., labs, activities, courses) within an engineering undergraduate curriculum. Beyond the well-established benefits of collaborative learning [9], we simultaneously and intentionally provided learning experiences to strengthen understanding the broader context, systems thinking, autonomy, and moral and ethical development. These included activities clarifying the role of the engineer in addressing significant societal challenges, allowing students to negotiate the course grade weighting, developing diagrams that link specific public policies to trends in public health, and a myriad of other learning experiences.

At this time, students who have been through this new experience are sophomores and juniors. The preliminary retention figures show that we have actually increased the number of female students for both cohorts from 2 (of 44) to 6 (of 40). The junior class has also seen an influx of female students from 4 (out of 40) to 6 (out of 36). While these numbers are small, they reverse two 15 -year trends in our program. They demonstrate a net increase in the number of female students from the freshmen to the junior year and they also show a decrease in the attrition rate of male students. We have also seen an increase in retention of male students, so that the overall retention rate from the freshman year has increased from $55 \%$ to $75 \%$.

In semi-structured interviews, conducted by a researcher external to our program, 5 female and 7 male students within these cohorts, answered two questions: 1)
Has seeing the connection between engineering and the world around you influenced your decision to say in Engineering? Why or why not?; 2) Is a collaborative learning environment important in your decision to stay in Engineering? Why or why not? While space limitations permit us from including quotations here, all but one male indicated that the connection to the world around them was a factor to varying degrees. All students also indicated that the collaborative environment was a positive element in their educational experience, although for different reasons. Before the conference, triangulating data on the test groups' motivation, value, and moral and ethical development will be analyzed. These will be presented at the FIE conference.

\section{ACKNOWLEDGMENT}

This work is supported in part by a grant from the National Science Foundation (Grant\#EEC-0530760). The viewpoints expressed are those of the authors and do not necessarily reflect those of the National Science Foundation.

\section{REFERENCES}

[1] "National Center for Education Statistics Completions Survey," Integrated Postsecondary Education Data System (IPEDS).

[2] S. H. Schwartz and T. Rubel, "Sex Differences in Value Priorities: Cross-Cultural and Multimethod Studies," Journal of Personality and Social Psychology, 89, 2005, pp. 1010-1028.

[3] "Beyond Bias and Barriers: Fulfilling the Potential of Women in Academic Science and Engineering," Washington D.C.: National Academies Press, 2007.

[4] T. K. DeBacker and H. M. Crowson, "Influences on cognitive engagement: Epistemological beliefs and need for closure," British Journal of Educational Psychology, 76, 2006, pp. 535-551.

[5] C. M. Mueller and C. S. Dweck, "Praise for Intelligence Can Undermine Children's Motivation and Performance," Journal of Personality and Social Psychology, 75, 1998, pp. 33-52.

[6] C. Burack and S. E. Franks, "Telling Stories About Engineering: Group Dynamics and Resistance to Diversity," NWSA Journal, 16, 2004, pp. 79-95.

[7] Heidi Loshbaugh and Brittany Claar, "Geeks Are Chic: Cultural Identity and Engineering Students' Pathways to the Profession," in Proc. ASEE, Honolulu, Hawaii (2007).

[8] L. Vanasupa, J. Stolk, T. Harding, and R. Savage, "A Systemic Model of Development: Strategically Enhancing Students' Cognitive, Psychomotor, Affective, and Social Development," in First International Conference on Research in Engineering Education, J. Froyd, Ed. Honolulu, Hawaii: IEEE, 2007.

[9] Prince, M. J., \& Felder, R. M. "Inductive Teaching and Learning Methods: Definitions Comparisons, and Research Bases." Journal of Engineering Education, 95, 2006, pp.1-16.

[10] P. P. Baard, E. L. Deci, and R. M. Ryan, "Intrinsic need satisfaction: A motivational basis of performance and well-being in two work settings," Journal of Applied Social Psychology, 34, 2004, pp. 2045206

[11] A. Assor, H. Kaplan, and G. Roth, "Choice is good, but relevance is excellent: Autonomy-enhancing and suppressing teacher behaviours predicting students' engagement in schoolwork," British Journal of Educational Psychology, 72, 2002, pp. 261-278. 